\title{
LUANA, LOURA DE OLHOS CLAROS
}

\section{Estudo da estética da arte e da comunicação evidenciam sentidos e significados que circulam, inclusive, nas telenovelas}

Há poucos meses ingressei como pesquisadora no projeto integrado de pesquisa Ficção e realidade: a telenovela no Brasil, o Brasil na telenovela, do Departamento de Comunicações e Artes da ECA-USP. Desde então tenho não só participado de instigantes seminários, como tenho passado a assistir a Rei do Gado, a novela das oito da Rede Globo. O que apresento aqui é um pequeno ensaio com as primeiras idéias a respeito dessa teleficção, bem como algumas reflexões sobre a metodologia de pesquisa, estas estimuladas, principalmente, pelas discussões surgidas nos seminários. Não se trata portanto de resultados finais ou de um amplo estudo científico, mas de aportes que podem interessar ao estudioso de arte e comunicação.

Desde os primeiros capítulos a que assisti, intrigou-me a imagem da protagonista - Luana - estrelada por Patrícia Pillar. Essa personagem, que devia fazer par romântico com Antônio Fagundes, o Rei do Gado, latifundiário paulista, tem origem humilde $\mathrm{e}$ rural. Iniciou sua história como uma bóia-

\section{A AUTORA}

Maria Cristina Castilho Costa

Professora Doutora do Departamento de Comunicações e Artes da ECA-USP. Trabalha com Estética dos Meios de Comunicação, é Especialista em Sociologia da Arte. cris@cyberspace.com.br fria, tendo depois se unido aos sem-terra até o momento em que, em meio a uma invasão, conhece Bruno Mezenga por quem se apaixona e com quem inicia um romance tumultuado.

Em todas as bem cuidadas cenas, Luana aparece louríssima e de olhos claros, encarnando uma jovem pura, ingênua, feminina $\mathrm{e}$ meiga, uma imagem fortemente contrastante com a maioria de nossos trabalhadores rurais ou os nossos sem-terra. Contrastante, inclusi$\mathrm{ve}, \mathrm{com}$ as demais personagens femininas da novela, todas elas muito morenas e com tipo físico bastante brasileiro, com exceção da exmulher de Bruno Mezenga, esta também loura e com a qual Luana faz contraponto, disputando com ela o pecuarista. Luana é portanto diferente, ímpar enquanto figura feminina nessa novela.

\section{MADONA-LUANA}

Interessei-me em indagar sobre as possíveis tradições estéticas inspiradoras dessa imagem delicada e simples, rústica mesmo, que parece tão estranha aos demais grupos sociais retratados no enredo, inclusive àqueles que a personagem inicialmente integra. Não foi difícil encontrar as possíveis influências dessa personagem assim concebida. Desde as madonas renascentistas, que povoam a pintura ocidental, com imagens de mulheres jovens, femininas com vestidos longos e aventais, trazendo na cabeça pe- 
quenos lenços, os quais mal conseguem prender a farta e anelada cabeleira loura.

Tanto a arte italiana como a flamenga estão repletas de exemplos de "MadonasLuanas", e não podemos esquecer que, no século XIX, as pinturas de Millet imortalizaram cenas da vida do campo na França.

Descobri, então, o que o próprio enredo acabou por revelar aos telespectadores: Luana não era uma moça caipira brasileira - no sentido dado à palavra por Antônio Cândido em Parceiros do Rio Bonito ${ }^{1}$ - mas uma camponesa de origem européia.

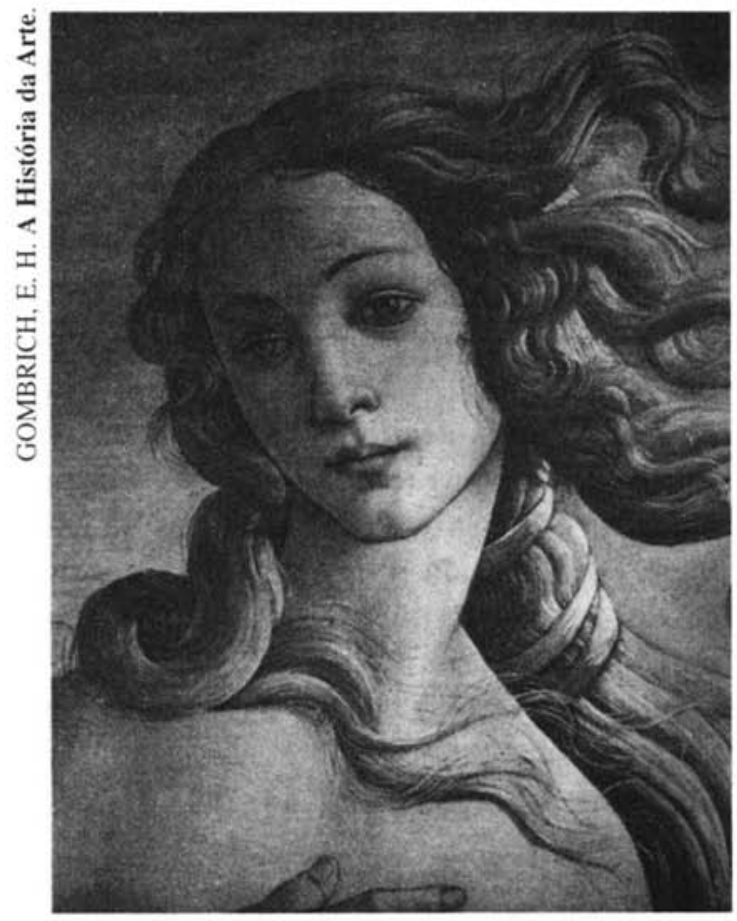

Detalhe da Vênus de Botticelli (Florença - 1485)
Outra fonte esclarecedora da imagem assumida por Patrícia Pillar nesse papel foi o último filme por ela encenado - $\mathbf{O}$ Quatrilho $^{2}$ - grande sucesso internacional, indicado inclusive para o Oscar de 96 e considerado como um marco de uma nova fase da cinematografia brasileira. Nesse filme, com uma imagem muito semelhante, mais sensual todavia, Patrícia encarna uma descendente de imigrantes europeus, também feminina, inocente e, ainda, com a audácia que caracterizou nossos imigrantes, pioneiros na agricultura de pequeno porte. Tanto quanto as camponesas da pintura européia, como essa personagem de $\mathbf{O}$ Quatrilho, Luana representa uma visão ro-

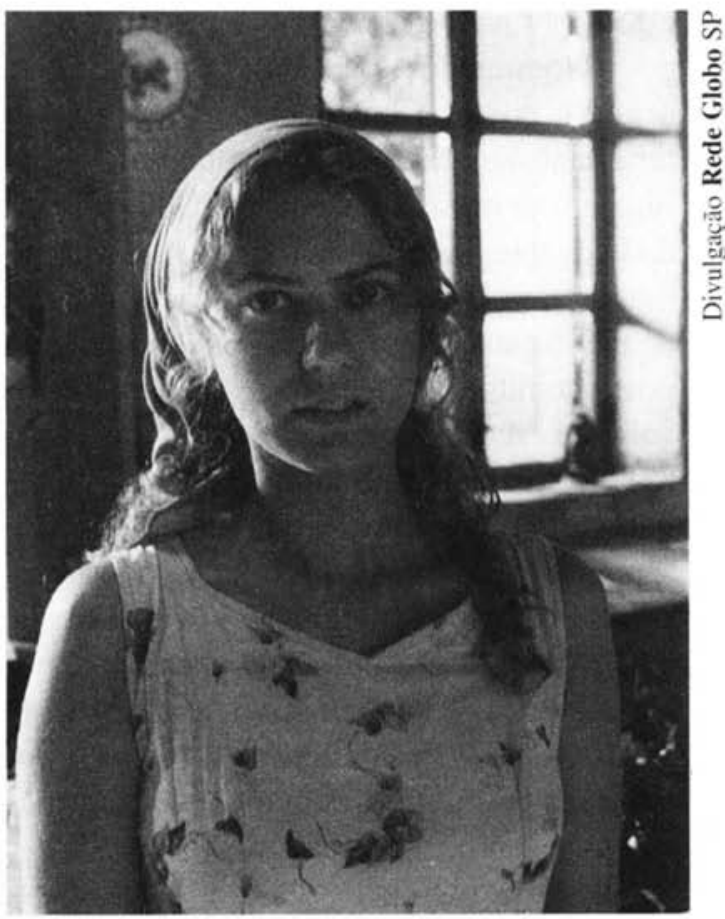

Patrícia Pillar como a Madona Luana, na novela Rei do Gado.

1. CÂNDIDO. Antônio. Parceiros do Rio Bonito: estudos sobre o caipira paulista e a transformação dos seus meios de vida. Rio de Janeiro: José Olímpio, 1964.

2. O Quatrilho

Direção: Fábio Barreto

Produção: Luís Carlos Barreto

Brasil/ 1996/ Cor/ Ficção (N.E.) 
mântica e bucólica do mundo rural, à maneira das obras dos pré-rafaelistas ${ }^{3}$.

Descobri assim o que, como disse, o próprio enredo viria a confirmar: Luana fora concebida a partir da imagem do campesinato europeu, assim como dos primeiros imigrantes que aqui chegaram, uma imagem idealizada tanto pela visão romântica do campesinato como pela saga da imigração. Uma imagem enaltecida também em outras culturas e de grande receptividade por parte do público internacional, já habituado a ela em filmes retratando a colonização dos Estados Unidos, ou comunidades rurais alternativas como os amish, em A Testemunha ${ }^{4}$, estrelado por Harrison Ford e Kelly MacGillis.

Orientando minhas indagações nesse sentido, procurei entender por que o autor teria lançado mão de uma protagonista cuja imagem se mostrava tão dissociada da realidade da telenovela - um mundo rural não só menos romântico como vivendo difíceis conflitos políticos e sociais. Encontrar a resposta no fato de a personagem Luana ser na verdade Marieta Berdinazi, herdeira e parente próxima das famílias de imigrantes italianos cujo conflito é o nó da novela, não satisfaz. Mesmo porque Rafaela, outra personagem feminina e igualmente aparentada dos Mezenga e Berdinazi, encarnada por Glória Pires - também protagonista de $\mathbf{O}$ Quatrilho - é decididamente morena e poderia ser confundida com qualquer das mu- lheres do meio rural, ou de uma cidade do interior brasileiro. Portanto, há maiores razões para essa "Luana-Madona" de olhos claros e imagem bucólica.

Talvez possamos buscar as explicações no próprio enredo do autor Benedito Rui Barbosa. Tendo que, para cumprir seu destino na trama televisiva, se afastar dos sem-terra e assumir o seu romance com o Rei do Gado, a personagem seria muito mais aceita pelo público se identificada com nossas imigrantes italianas. Afinal o enlace dos dois reproduz uma união consagrada no sudeste brasileiro: a de um latifundiário homem ou mulher - e um(a) imigrante. Essas uniões, tema de grandes obras literárias como Os ossos do barão ${ }^{5}$, de Jorge de Andrade, reuniam fazendeiros decadentes a imigrantes enriquecidos ou ricos cafeicultores a recém-chegados camponeses.

Outras novelas brasileiras já tiveram nesses romances sua trama principal, sempre numa nítida defesa dos casamentos interétnicos e interclassistas. Seria possível e tão aceito o romance entre Luana e Bruno Mezenga se ela fosse uma mulher rude e sofrida como nossos bóiasfrias, ou engajada numa das lutas políticas mais conscientes e organizadas do país no momento?

Por ser "estrangeira", Luana dá mais liberdade ao autor, que pode cometer des-

3. Os grandes pintores que precederam Rafael e o influenciaram. Rafael - Raffaello Santi ou Sanzio (Urbino 6/04/1483 Roma 6/04/1520). Pintor italiano que adotou as idéias da Antigüidade Clássica. Discípulo de Perugino, foi influenciado por Leonardo da Vinci. Miguel Ângelo, Sebastiano del Piombo e Frei Bartolomeu. Pintou, entre outras obras, as conhecidas Madonas: "Retrato de Mulher Grávida": "Madona Sistina": "Madona da Cadeira"; "Madona do Grão-Duque": "Madona de São Sisto". (N.E.)

4. A testemunha (Witness)

Direção: Peter Weir

EUA/1985/ficção

Amish - seita anabatista dos EUA cujos seguidores vivem em comunidades adotando estilo de vida semelhante ao existente na Europa, no Séc. XVIII. Rejeitam a tecnologia, a indústria e até a energia elétrica. (N.E.)

5. ANDRADE, Jorge. A Escada e Os ossos do Barão. São Paulo: Brasiliense, 1964. 
lizes políticos e ideológicos como fazê-la deixar o movimento e se dedicar a seu próprio destino e à sua luta pessoal - amor pelo latifundiário. Também por essa posição, ao mesmo tempo ambígua e indefinida, ela pode entrar e sair do acampamento dos sem-terra sem que dela se cobre um engajamento mais profundo. A protagonista pode, dessa maneira, ser aceita pelos diversos grupos sociais do universo rural, dos trabalhadores aos fazendeiros, transitando por todos eles sem pertencer ou representar nenhum.

Assim, a união de Luana e o Rei do Gado, bem como o nascimento de um novo herdeiro - previsto no enredo até esse momento em que escrevo este ensaio tem o apoio desse público tão amplo quanto heterogêneo que é o da telenovela. Ela satisfaz por respeitar também, ao menos no imaginário, valores ideológicos importantes do povo brasileiro como o orgulho de uma origem latina européia, sempre lembrando Darcy Ribeiro em seus trabalhos sobre a composição de nosso povo e os princípios de nossa identidade. Essa trama encontra respaldo no anseio pelo branqueamento da raça presente nos nossos mais diferentes grupos étnicos, como demonstraram os estudos sobre o comportamento étnico e racial da sociedade brasileira. Assim, Luana penetra nos lares brasileiros sem conflitos e provocando inquestionável empatia e benevolência.

\section{ANÁLISE QUALITATIVA}

Por outro lado, seu "deslocamento" em relação aos grupos sociais rurais mencionados - bóias-frias e sem-terra - dá ao autor a liberdade necessária para continuar orientando suas personagens ao encontro dos anseios do público, aspecto característi- co das telenovelas, o qual se veria comprometido caso mesclasse o conflito amoroso ao conflito social.

Mas a análise qualitativa que aqui apenas se inicia abre espaço para novos desdobramentos. Podemos argumentar, por exemplo, que como O Quatrilho, Rei do Gado deverá chegar às televisões do mundo todo num processo de divulgação cada vez mais amplo, possibilitado tanto pela globalização dos meios de comunicação quanto pelo próprio sucesso das novelas brasileiras no exterior. Uma protagonista cuja imagem tenha um referente na tradição cultural do público internacional, torna mais fácil a sua identificação com ela, aspecto de maior importância na fruição estética. Bem, mas isso exige novas interpretações e o nosso objetivo nesse artigo não é o estudo exaustivo dessas hipóteses.

O que queremos deixar registrado é, na verdade, menos as questões a respeito dos cabelos louros de Luana do que as possibilidades que a análise qualitativa nos permite no desvendamento do universo imaginário da obra de arte e dos processos de comunicação. Um infindável universo de sentidos e significados se abre, permitindo integrar tradições artísticas e culturais, bem como importantes análises sociais e históricas.

O estudo de caso, na medida em que se sustenta em princípios teóricos fidedignos e em interpretações textuais amparadas por sentidos amplamente aceitos - como por exemplo a que relaciona a imagem da Luana com a das camponesas da arte européia - , ganha a necessária universalidade. $\mathrm{E}$ assim fazemos Luana entrar não só em nossos lares como também numa longa e ampla tradição estética. 
Resumo: Destacando a importância da análise qualitativa no estudo da arte e da comunicação, a autora analisa como a opção estética por uma atriz loura na construção da personagem Luana, na novela Rei do Gado, veiculada pela Rede Globo, no segundo semestre de 1996, reafirma a aspiraçāo ao branqueamento e identidade com o europeu que permanece no imaginário nacional.

Palavras-chave: análise qualitativa, estética, comunicação, arte, Luana, Rei do Gado
Abstract: While pointing out the importance of qualitative analysis in the study of art and communication, the author analyses in what way the aesthetic decision for a blond actress in the elaboration of the character Luana of the telenovela Rei do Gado, broadcast on the TV network Rede Globo, in the second half of 1996, reinforces the aspiration for whitening and for an identification with the European, which is still present in the national imaginary.

Key-words: qualitative analysis, aesthetics, communication art, Luana, Rei do Gado 